\title{
NONLINEAR MULTILEVEL ANALYSIS OF REINFORCED CONCRETE FRAMES
}

\author{
Pui Lam NG ${ }^{\mathrm{a}, \mathrm{b}}$, Jeffery Yuet Kee LAM ${ }^{\mathrm{a}, \mathrm{c}}$, Albert Kwok Hung KWAN ${ }^{\mathrm{a}}$ \\ ${ }^{a}$ Department of Civil Engineering, The University of Hong Kong, Pokfulam, Hong Kong, China \\ ${ }^{b}$ Faculty of Civil Engineering, Vilnius Gediminas Technical University, \\ Sauletekio al. 11, LT-10223 Vilnius, Lithuania \\ ${ }^{c}$ AECOM, Hong Kong, China
}

Received 26 December 2015; accepted 02 February 2015

\begin{abstract}
Full range analysis of reinforced concrete (RC) members covering the post-crack and post-peak regimes is important for obtaining the deformation response and failure mode of structural members. When a RC member is subject to an increasing external load, the critical sections would exhibit cracking and/or softening. Due to stress relief effect in the proximity of crack opening and plastic hinging, unloading may occur at the adjacent regions. The variable stress states of discrete sections would lead to sectional variation of stiffness, which could not be accounted for by conventional structural analysis methods. In this paper, a nonlinear multilevel analysis method for RC frames whereby the frame members are divided into subelements and sectional analysis is utilised to evaluate stiffness degradation and strength deterioration is developed. At sectional level, the secant stiffness is determined from moment-curvature relation, where the curvature is evaluated based on both transverse displacements and section rotations of the frame member. Unloading and reloading behaviour of concrete and reinforcing steel is simulated. In implementing the multilevel analysis, secant iteration is performed in each step of displacement increment to obtain the convergent solution satisfying equilibrium. Numerical example of RC frame is presented to demonstrate the applicability and accuracy of the proposed nonlinear multilevel analysis method.
\end{abstract}

Keywords: multilevel analysis, reinforced concrete frames, sectional analysis, stiffness degradation, stress relief, strain localisation, unloading.

\section{Introduction}

By extending the analysis of reinforced concrete (RC) members into post-crack and post-peak regimes, the full range analysis of structural members is useful for acquiring their deformation response and failure mode, as well as collapse mechanism in forensic structural engineering. However, the structural behaviour of RC members in post-crack and post-peak stages is complicated. Consider a RC member subjected to an increasing level of external load, at certain load level, the critical section starts to crack and softens. When the external load continues to increase, the cracked section would exhibit crack propagation and further softening, while other uncracked sections might become critical and exhibits cracking and softening. At the occurrence of crack opening, which may encompass crack initiation and crack propagation, there would be stress redistribution between concrete and reinforcing steel. In the region close to the crack, the stresses of concrete might decrease due to stress relief effect, hence unloading might occur at the associated sections. Besides, when the deformation of member is large, plastic hinge may form where there is high intensity of rotation with occurrence of strain localisa- 
tion. In the proximity of plastic hinging, the stresses of concrete and steel might be relieved due to strain reversal effect, thus unloading might happen at the associated sections. Along the RC member, the stress states of discrete sections would be variable. The different degrees of stiffness degradation lead to sectional variation of stiffness, which could not be accounted for by conventional methods of structural analysis.

To tackle the above difficulty, the nonlinear multilevel analysis methodology of RC structures is developed by the authors. The multilevel analysis of structures involves breaking down the structure into lower level sub-elements and conducting analysis at the sub-element level. The process encompasses substructuring and static condensation. Substructuring technique refers to subdividing the large structure into components, or substructures. It was first implemented by Przemieniecki (1963), who analysed each substructure separately by assuming fixity at all substructure interface boundaries initially, and followed by simultaneous relaxation of all boundary fixities to determine the boundary displacements from the solution of equilibrium equations. Static condensation refers to the formation of equivalent stiffness matrix for exterior nodes that includes all interior effects, and such procedure greatly reduces the degrees of freedom in solving matrix equations.

The mathematical theory of substructuring in analysis of linear elastic problems is well established. Row and Powell (1978) devised a general multilevel substructuring procedure for static analysis, and developed a static condensation procedure incorporating Choleski decomposition. Subsequently, Leung and Cheung (1981) introduced the two-level finite element method, aiming to enhance the computational efficiency in solving large-scale frame problems. In their method, each substructure (or referred to as super-element) is defined by the analyst and is assembled in accordance with the pre-assigned master nodes, at which connections between substructures are made. Inside a substructure, the nodal displacements are determined from the interpolating function of the master nodes.

One of the practical examples of engineering applications of multilevel analysis method was the elastic analysis of steel girder frame structure conducted by Dodds and Lopez (1980). The plane frame and girder frame members were assigned to the first level of substructure, whereas the second and third levels of substructure were generated by subdividing the girder into triangular and quadratic plane stress finite elements. They reported a $99 \%$ reduction in computer time in the solution process by using substructuring technique. Furthermore, the substructuring technique has been applied to various engineering fields such as structural dynamics (Leung 1989), soil-structure interaction (Lai, Booker 1991), and automatic design optimisation problems (Ding, Esping 1991).

The substructuring technique has also been applied to the nonlinear analyses such as elasto-plastic problem regarding steel members (Roeck et al. 1989) and buckling problem (Huang, Wang 1993). For analysis of nonlinear problems, the load is applied typically in the form of either force or displacement increment steps. Within each incremental step, iteration process is required to achieve convergence. Since the structure stiffness may vary among iterations, reformulation and reassembly of the stiffness matrices are necessary. This costs enormous computational resource requirements. Nevertheless, in RC structures, the major sources of nonlinearity arise from cracking and plastic hinging, which are often confined to localised regions of the structure. By condensing the size of problem with respect to the undamaged and damaged status, the computation can be substantially economised. This may be accomplished by dividing the structure into two sets of substructures (Lam et al. 2007; Lam 2009). The first set is referred to as elastic substructures, which are known to remain elastic throughout the analysis. The matrix formulation of the elastic substructures is performed only once prior to the start of nonlinear analysis. The second set is referred to as nonlinear substructures, which are remainder of the structure whose stiffnesses may be modified during load increments and numerical iterations.

In the current research, the nonlinear multilevel analysis method for concrete frames, whereby the frame member is divided into sub-elements and the member analysis is undertaken in conjunction with sectional analysis to evaluate the actual load-deflection response, is developed. At sectional level, the stiffness of sub-elements is determined from the moment-curvature relations, in which the curvature is evaluated based on the transverse displacements and section rotations of the member. The procedures of the multilevel analysis method will be further explained hereunder. 


\section{Substructuring and condensation technique}

The process of substructuring is basically a means of solving a discretized continuum problem which involves large number of unknowns by breaking it down into a series of lower level problems. At the lower level, prior to the static condensation and substructure assembly, all the internal degrees of freedom associated with the internal nodes of a substructure are eliminated. The resulting system, which is called condensed substructure, consists of only the boundary degrees of freedom associated with the boundary nodes. The condensed substructure in which all interior effects are inclusive is assembled with other substructures through connections at their boundary nodes.

A brief overview of the mathematical basis of substructuring for static structural analysis is presented in the following. The force-displacement relation of a substructure is given by Eq. (1):

$$
\left[\begin{array}{cc}
K_{i i}^{(j)} & K_{i b}^{(j)} \\
K_{b i}^{(j)} & K_{b b}^{(j)}
\end{array}\right]\left\{\begin{array}{c}
U_{i}^{(j)} \\
U_{b}^{(j)}
\end{array}\right\}=\left\{\begin{array}{c}
P_{i}^{(j)} \\
P_{b}^{(j)}
\end{array}\right\},
$$

in which $\left[K_{i i}^{(j)}\right],\left[K_{i b}^{(j)}\right],\left[K_{b i}^{(j)}\right]$ and $\left[K_{b b}^{(j)}\right]$ are the stiffness submatrices, $\left\{U_{i}^{(j)}\right\}$ and $\left\{U_{b}^{(j)}\right\}$ are respectively the displacements at the internal and boundary nodes, $\left\{P_{i}^{(j)}\right\}$ and $\left\{P_{b}^{(j)}\right\}$ are respectively the external force vectors at the internal and boundary nodes, and superscript ${ }^{(j)}$ refers to the $j^{\text {th }}$ substructure.

After static condensation, the equations for the condensed matrix consisting of boundary nodes only are shown as follows:

$$
\begin{gathered}
{\left[K_{b}^{(j)}\right]\left\{U_{b}^{(j)}\right\}=\left\{\bar{P}_{b}^{(j)}\right\} ;} \\
{\left[K_{b}^{(j)}\right]=\left[K_{b b}^{(j)}\right]-\left[K_{b i}^{(j)}\right]\left[K_{i i}^{(j)}\right]^{-1}\left[K_{i b}^{(j)}\right] ;} \\
\left\{\bar{P}_{b}^{(j)}\right\}=\left\{P_{b}^{(j)}\right\}-\left[K_{b i}^{(j)}\right]\left[K_{i i}^{(j)}\right]^{-1}\left\{P_{i}^{(j)}\right\},
\end{gathered}
$$

where $\left[K_{b}^{(j)}\right]$ and $\left\{\bar{P}_{b}^{(j)}\right\}$ are respectively the effective substructure stiffness matrix and the effective substructure force vector.

In the present study, a frame member is divided into a number of sub-elements, in which the stiffness of each sub-element is determined from the momentcurvature relations presented in later paragraphs of this paper. The stiffness equations of a sub-element can be partitioned as given by Eq. (3):

$$
\left[\begin{array}{ll}
K_{l l} & K_{l r} \\
K_{r l} & K_{r r}
\end{array}\right]\left\{\begin{array}{c}
U_{l} \\
U_{r}
\end{array}\right\}=\left\{\begin{array}{c}
P_{l} \\
P_{r}
\end{array}\right\},
$$

in which $\left[K_{l l}\right],\left[K_{l r}\right],\left[K_{r l}\right]$ and $\left[K_{r r}\right]$ are the partitioned stiffness submatrices, $\left\{U_{l}\right\}$ and $\left\{U_{r}\right\}$ are the displacements of the end nodes of a sub-element, $\left\{P_{l}\right\}$ and $\left\{P_{r}\right\}$ are the corresponding nodal force vectors of the end nodes of a sub-element.

Let $N$ be the number of sub-elements in a frame member. The stiffness equations of the frame member assembled from the $N$ sub-elements are expressed as:

$$
\begin{gathered}
{\left[\begin{array}{ccc}
K_{l l}^{(1)} & L^{\mathrm{T}} & 0 \\
L & K & R \\
0 & R^{\mathrm{T}} & K_{r r}^{(N)}
\end{array}\right]\left\{\begin{array}{c}
U_{l}^{(1)} \\
X \\
U_{r}^{(N)}
\end{array}\right\}=\left\{\begin{array}{c}
P_{l}^{(1)} \\
P \\
P_{r}^{(N)}
\end{array}\right\} ;} \\
{[L]=\left[K_{l r}^{(1)}, 0 \ldots, 0\right]^{\mathrm{T}} ;} \\
{[R]=\left[0,0 \ldots, K_{r l}^{(N)}\right]^{\mathrm{T}},}
\end{gathered}
$$

where $[K]$ is a matrix determined from the assembly of the stiffness submatrices of the internal nodes, $\{X\}$ and $\{P\}$ are respectively the displacements and equivalent force vectors of internal nodes, superscript ${ }^{(1)}$ and superscript ${ }^{(N)}$ represent the $1^{\text {st }}$ sub-element and the $N^{\text {th }}$ sub-element, respectively.

By eliminating $\{X\}$ from Eq. (4a), the stiffness matrix, nodal displacements and equivalent force vector of the condensed structure are given by:

$$
\begin{gathered}
{\left[K_{b}\right]\left\{U_{b}\right\}=\left\{P_{b}\right\} ;} \\
{\left[K_{b}\right]=\left[\begin{array}{cc}
K_{l l}^{(1)}-L^{\mathrm{T}} K^{-1} L & -L^{\mathrm{T}} K^{-1} R \\
-R^{\mathrm{T}} K^{-1} L & K_{r r}^{(N)}-R^{\mathrm{T}} K^{-1} R
\end{array}\right] ;} \\
\left\{U_{b}\right\}=\left\{U_{l}^{(1)}, U_{r}^{(N)}\right\}^{\mathrm{T}} ; \\
\left\{P_{b}\right\}=\left\{P_{l}^{(1)}-L^{\mathrm{T}} K^{-1} P, P_{r}^{(N)}-R^{\mathrm{T}} K^{-1} P\right\} .
\end{gathered}
$$

Having determined the substructure matrices, the stiffness matrices and force vectors of all substructures are assembled to form the matrix equation of the whole structure:

$$
[K]\{U\}=\{F\} .
$$

For each displacement increment and numerical iteration, the displacement vector $\left\{U_{b}^{(j)}\right\}$ for the $j^{\text {th }}$ substructure is extracted from $\{U\}$ and substituted into Eq. (7) to obtain the translational and rotational displacements of internal nodes.

$$
\left\{U_{i}^{(j)}\right\}=-\left[K_{i i}^{(j)}\right]^{-1}\left[K_{i b}^{(j)}\right]\left\{U_{b}^{(j)}\right\}+\left[K_{i i}^{(j)}\right]^{-1}\left\{P_{i}^{(j)}\right\}
$$




\section{Material Modelling}

Nonlinear stress-strain constitutive relations of concrete and reinforcing steel are incorporated in the study. Stress-path dependent unloading and reloading curves are included in the material modelling so as to allow for possible unloading and reloading due to the aforementioned stress relief and strain reversal effects. As explained in the foregoing, even under monotonically increasing loading, sections in the proximity of crack opening and plastic hinging may subject to unloading, while if the loading is further increased, the unloaded sections may experience reloading. These phenomena have significant effects on the post-crack and post-peak behavioural characteristics of RC members.

It should be noted that for the sign convention, compressive stresses and strains are taken as positive while those in tension are negative, sagging moment is taken as positive while hogging moment is taken as negative.

\subsection{Stress-strain relationship of concrete}

For concrete under compression, the compressive stress-strain curve proposed by Saenz (1964) for normal strength concrete is employed. The relationship between the concrete compressive stress $\sigma_{c}$ and the concrete compressive strain $\varepsilon_{c}$ is given by Eq. (8), where $E_{0}$ is the initial elastic modulus of concrete, $\varepsilon_{c o}$ is the concrete strain at peak compressive stress, and $E_{c o}$ is the secant modulus at peak compressive stress.

$$
\sigma_{c}=\frac{E_{0} \varepsilon_{c}}{1+\left(\frac{E_{0}}{E_{c o}}-2\right)\left(\frac{\varepsilon_{c}}{\varepsilon_{c o}}\right)+\left(\frac{\varepsilon_{c}}{\varepsilon_{c o}}\right)^{2}} .
$$

Unloading and reloading path is assumed to follow the gradient of $E_{0}$ at starting point of unloading until it reaches zero stress. If reloading takes place at the unloading stage, the same unloading path is retracted until reaching the envelope curve of Eq. (8).

For concrete under tension, the tensile stressstrain curve proposed by Guo and Zhang (1987) is adopted. The relationship between the concrete tensile stress $\sigma_{t}$ and the concrete tensile strain $\varepsilon_{t}$ is given by Eq. (9), where $f_{t o}$ is the peak tensile stress, $\varepsilon_{t o}$ is the strain at peak tensile stress, and $\alpha$ is a parameter dependent on the concrete grade.

$$
\begin{gathered}
\sigma_{t}=f_{t o}\left[1.2\left(\frac{\varepsilon_{t}}{\varepsilon_{t o}}\right)-0.2\left(\frac{\varepsilon_{t}}{\varepsilon_{t o}}\right)^{6}\right] \text { for } \varepsilon_{t} \leq \varepsilon_{t o} ; \\
\sigma_{t}=\frac{f_{t o}\left(\frac{\varepsilon_{t}}{\varepsilon_{t o}}\right)}{\alpha\left(\frac{\varepsilon_{t}}{\varepsilon_{t o}}-1\right)^{1.7}+\left(\frac{\varepsilon_{t}}{\varepsilon_{t o}}\right)} \text { for } \varepsilon_{t}>\varepsilon_{t o} .
\end{gathered}
$$

Unloading path is assumed to follow the gradient of secant modulus at starting point of unloading (i.e. the path directs towards point of zero strain from the starting point of unloading). If reloading takes place at the unloading stage, the same unloading path is retracted until reaching the envelope curve of Eq. (9).

\subsection{Stress-strain relationship of reinforcing steel}

A bilinear stress-strain relationship of reinforcing steel is adopted. It comprises an initial elastic region with elastic modulus $E_{\mathrm{s}}$ and a yield plateau of yield stress $f_{y}$. The relationship between the steel stress $\sigma_{s}$ and the steel strain $\varepsilon_{s}$ is given by Eq. (10), where $\varepsilon_{p s}$ is the residual plastic strain. Bauschinger effect is not taken into consideration. If unloading occurs after yielding of steel, the stress decreases by following a straight line having the same gradient as $E_{s}$ until it reaches zero.

$$
\begin{aligned}
& \text { At elastic stage: } \sigma_{s}=E_{s} \varepsilon_{s} \text { for } \varepsilon_{s} \leq f_{y} / E_{s} \text {; } \\
& \text { After yielding: } \sigma_{s}=f_{y} \text { for } \varepsilon_{s}>f_{y} / E_{s} \text {; } \\
& \text { During unloading or reloading: } \\
& \sigma_{s}=E_{s}\left(\varepsilon_{s}-\varepsilon_{p s}\right) .
\end{aligned}
$$

\section{Numerical Procedures}

Figure 1 depicts the flowchart of procedures of the multilevel analysis method. The nonlinear multilevel analysis method for RC frames comprises two levels of nonlinear substructuring technique, and involves nonlinear member analysis and nonlinear sectional analysis. The numerical procedures are described in detail below.

\subsection{Nonlinear sectional analysis}

The assumption of plane sections remain plane after deformation is adopted. It implies that the bending strain in the section is proportional to the distance from the neutral axis. Define $x$-direction to be parallel to the neutral axis and $y$-direction to be perpendicular to the neutral axis. Denote the curvatures of the beam 
about the $x$ - and $y$ - axes respectively by $\kappa_{x}$ and $\kappa_{y}$, the strain in the beam section is given by:

$$
\varepsilon=\varepsilon_{\mathrm{A}}+\kappa_{y} x+\kappa_{x} y
$$

where $\varepsilon_{\mathrm{A}}$ is the axial strain at sectional centroid and $(x, y)$ indicates the location of the point being considered. The strains of concrete in compression zone and tension zone and the strain of reinforcing steel may be evaluated from Eq. (11).

Having determined the strains, the corresponding stresses developed in the concrete and steel reinforcement may be computed from the corresponding stress-strain relationships of the materials. The stresses developed in the section must satisfy the conditions of axial and moment equilibria. The equilibrium equations are expressed as follows:

$$
\left[\begin{array}{c}
P_{\mathrm{A}} \\
M_{x} \\
M_{y}
\end{array}\right]=\left[\begin{array}{c}
P_{\mathrm{A}} \\
M_{x} \\
M_{y}
\end{array}\right]_{c}+\left[\begin{array}{c}
P_{\mathrm{A}} \\
M_{x} \\
M_{y}
\end{array}\right]_{s}=\left[\begin{array}{c}
\int \sigma d A_{c} \\
\int \sigma y d A_{c} \\
\int \sigma x d A_{c}
\end{array}\right]+\left[\begin{array}{c}
\sum \sigma A_{s} \\
\sum \sigma y A_{s} \\
\sum \sigma x A_{s}
\end{array}\right],
$$

where $P_{\mathrm{A}}$ is the applied axial load, $M_{x}$ and $M_{y}$ are the resisting moments about $y$-axis and $x$-axis, $d A_{c}$ is the part of sectional area being considered, $A_{s}$ is the area of reinforcing steel and subscripts ${ }_{c}$ and ${ }_{s}$ represent concrete and steel respectively. If there is no axial load applied to the member, a value of zero is substituted for $P_{\mathrm{A}}$. In the computer implementation of Eq. (12), numerical integration using Gauss quadrature is performed.

After obtaining the curvatures from the transverse displacements and section rotations of the member, an iterative process based on Newton-Raphson's method is employed to calculate the axial strain $\varepsilon_{\mathrm{A}}$. At the start of iteration, suppose there is an unbalanced axial force $Q$, the value of axial strain in the $(i)^{\text {th }}$ iteration is evaluated as:

$$
\left(\varepsilon_{\mathrm{A}}\right)_{i}=\left(\varepsilon_{\mathrm{A}}\right)_{i-1}-\frac{\left(Q_{i}-Q_{i-1}\right)}{\frac{\partial Q}{\partial \varepsilon}},
$$

where $Q_{i-1}$ and $Q_{i}$ are respectively the unbalanced axial force at the $(i-1)^{\text {th }}$ and $(i)^{\text {th }}$ iteration, $\partial Q / \partial \varepsilon$ is the finite difference approximation corresponding to axial strain interval limited by $\left[\varepsilon_{\mathrm{A}}-(0.5) \Delta \varepsilon_{\mathrm{A}}, \varepsilon_{\mathrm{A}}+(0.5)\right.$ $\left.\Delta \varepsilon_{\mathrm{A}}\right]$. A value of the axial strain increment $\Delta \varepsilon_{\mathrm{A}}$ equal to $1.0 \times 10^{-6}$ appears to be numerically stable. The iteration is repeated until attaining convergence, where the unbalanced axial force is smaller than the allowable tolerance. This is usually rapidly achieved.

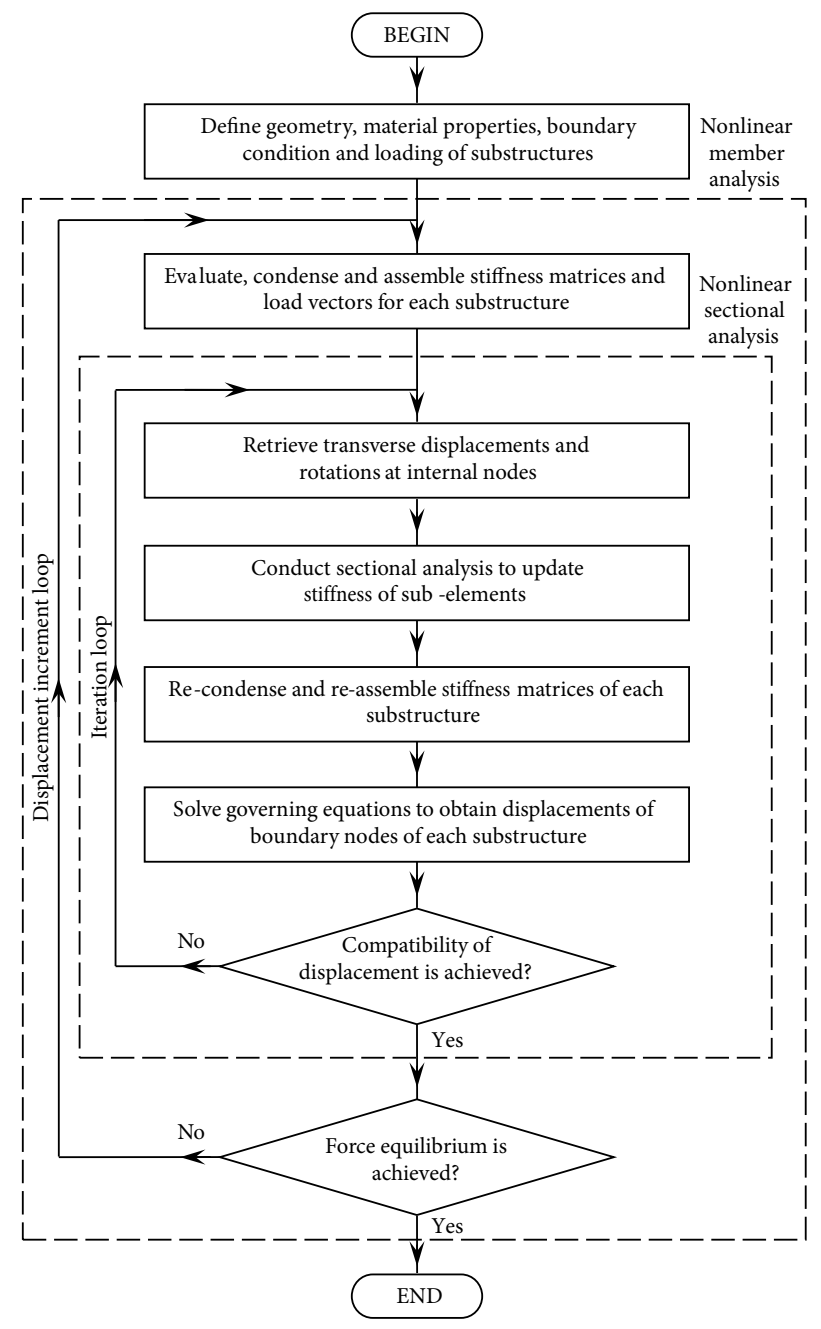

Fig. 1. Flowchart of nonlinear multilevel analysis

Having determined the value of $\varepsilon_{\mathrm{A}}$ by numerical iteration, the moment equilibrium condition is employed to evaluate the resisting moments. With the inclusion of unloading and reloading curves in the materials constitutive model, the moment-curvature relation so obtained is able to account for strain reversal effects and is well suited for post-crack and postpeak analysis. The flexural stiffness of the sub-element is updated in accordance with the tangent stiffness matrix of the section, $[S]$, which is determined using finite difference approximation as given by Eq. (14). With the known moment and curvature values, the secant stiffness of the sub-element is obtained.

$$
[S]=\left[\begin{array}{ccc}
\frac{\partial P_{\mathrm{A}}}{\partial \varepsilon} & \frac{\partial P_{\mathrm{A}}}{\partial \kappa_{y}} & \frac{\partial P_{\mathrm{A}}}{\partial \kappa_{x}} \\
\frac{\partial M_{x}}{\partial \varepsilon} & \frac{\partial M_{x}}{\partial \kappa_{y}} & \frac{\partial M_{x}}{\partial \kappa_{x}} \\
\frac{\partial M_{y}}{\partial \varepsilon} & \frac{\partial M_{y}}{\partial \kappa_{y}} & \frac{\partial M_{y}}{\partial \kappa_{x}}
\end{array}\right] .
$$


The updated secant stiffness of the sub-elements will be assembled into the condensed frame member and used for the higher level analysis.

\subsection{Nonlinear member analysis}

For each member of a RC frame, it is divided into a number of substructures, which are connected at the boundary nodes. Within each substructure, the topology of sub-elements is defined by the internal nodes, which may be located at equal intervals or designated by the analyst. For illustration purpose, Figure 2 shows a continuous RC beam composed of three substructures which are modelled by plane frame elements and the beam is subdivided into a total of $\left(N_{1}+N_{2}+N_{3}\right)$ sub-elements. The first substructure has $\left(N_{1}-1\right)$ internal nodes, whilst the second and the third substructures have $\left(\mathrm{N}_{2}-1\right)$ and $\left(\mathrm{N}_{3}-1\right)$, respectively. The material properties and loading conditions of the member is used for defining the initial conditions of the subelements. Prior to the member analysis, nonlinear sectional analysis for evaluating the stiffness of all subelements is performed.

To model the effect of plastic hinging, suitable element size and element properties need to be employed to represent the plastic hinge region. From the authors' experience, numerical snap-back instability might occur if the assumed plastic hinge length differs significantly from the actual value, and if improper element size is used where the length of element is well shorter than the plastic hinge length. The plastic hinge length of reinforced concrete members had been vastly researched over the past decades and a number of prediction formulas had been proposed for beams (Mattock 1964, 1967; Corley 1966; Mendis 2001) and for columns (Park et al. 1982; Zahn et al. 1983; Zahn 1985; Paulay, Priestley 1992; Bayrak, Sheikh 1997; Paultre et al. 2001). By comparing the experimental plastic hinge length results of reference concrete members such as those tested by Tanaka and Park (1990) against

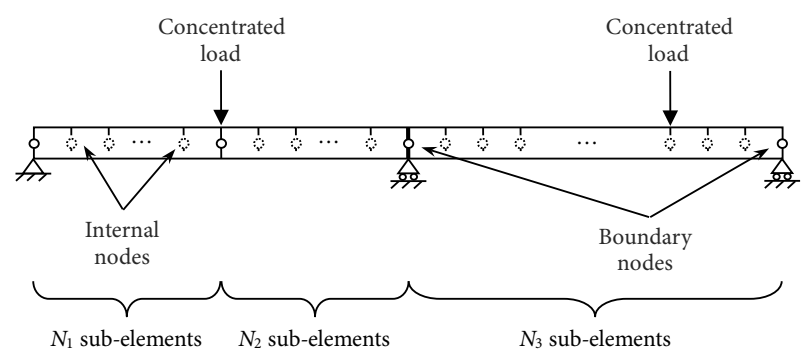

Fig. 2. Substructuring of two-span continuous beam the predictions by different formulas, the mean value of formulas proposed by Corley (1966) and Mendis (2001) for beams and the formula proposed by Zahn et al. (1983) and Zahn (1985) for columns were found to be leading to desirable results (Lam 2009). Upon the formation of plastic hinge, the elements representing the plastic hinge zone should be altered to allow for the possible rigid-body rotation and inelastic curvature pertinent to the plastic hinging behaviour. The shear modulus is adjusted by the shear retention factor to reflect the reduction of flexural shear rigidity ( $\mathrm{Ng} 2007)$. The bond slip between concrete and reinforcement is simulated by connecting rotational springs with frame element in series, and the stiffness of rotational springs is established from the actual moment-curvature relations (Lam 2009).

For a given RC frame, it is analysed by applying prescribed incremental displacement to the control nodes of the members in small steps. Under a prescribed displacement, having condensed the sub-elements into a frame element and assembled the condensed frame elements, Eq. (6) is solved for the translational and rotational displacements of the boundary nodes. From the nodal displacements of boundary nodes, the nodal displacements of each internal node can be determined based on Eq. (7). The curvature of each sub-element is then evaluated based on both transverse displacements and section rotations of the sub-element. From the curvatures so obtained, the strain distribution can be determined as per Eq. (11), and the corresponding stresses developed in concrete and reinforcing steel can be computed according to the respective material stress-strain relationships. The axial strain which satisfies the axial equilibrium condition is evaluated by the iterative process as formulated in Eq. (13). The stiffness of the sub-elements is determined as the secant slope of the moment-curvature relation. Consequently, the condensed frame element is formulated again and assembled into the global structure for frame analysis. The above numerical procedure is repeated for each displacement increment step until the required load level is attained.

\section{Numerical example}

A two storey RC frame specimen, which was tested by Vecchio and Emara (1992), is analysed. It has a centre to centre span of $3500 \mathrm{~mm}$ and a storey height of $2000 \mathrm{~mm}$ as shown in Figure 3. The dimensions of all 
frame members were $300 \mathrm{~mm}$ wide by $400 \mathrm{~mm}$ deep. All members were similarly reinforced with four No. 20 deformed steel bars as tension reinforcement, four No. 20 deformed steel bars as compression reinforcement and No. 10 closed stirrups with a centre to centre spacing of $125 \mathrm{~mm}$ as shear reinforcement. The longitudinal reinforcement was anchored at all ends of members by welding the steel bars to stiff bearing plates. The geometry and section details of frame members are depicted in Figure 3.

The material properties of the RC frame are as follows. The compression strength of concrete was 30 $\mathrm{MPa}$. The tensile strength and initial elastic modulus of concrete were taken to be $1.8 \mathrm{MPa}$ and $26 \mathrm{GPa}$ respectively. The longitudinal reinforcement had a yield strength of $418 \mathrm{MPa}$, an ultimate stress of $596 \mathrm{MPa}$, and an elastic modulus of $192.5 \mathrm{GPa}$. The shear reinforcement had a yield strength of $454 \mathrm{MPa}$ and an ultimate stress of $640 \mathrm{MPa}$. In the load test, a constant axial load of $700 \mathrm{kN}$ was first applied to each column under force-control mode. Lateral load was then monotonically applied under displacement-control mode, until the ultimate capacity of the frame was reached.
The nonlinear multilevel analysis is employed to determine the load-deflection response of the RC frame. The frame is modelled by four columns $(\mathrm{C} 1$, $\mathrm{C} 2, \mathrm{C} 3$ and $\mathrm{C} 4$ ) and two beams (B1 and B2), as shown in Figure 4. Each column member is subdivided into 8 sub-elements of identical length and has 2 external nodes and 7 interior nodes, whereas each beam member is subdivided into 12 sub-elements of identical length and has 2 external nodes and 11 interior nodes. The constant axial load of $700 \mathrm{kN}$ applied to each column is simulated by prescribed axial forces as the initial condition, while the lateral load is simulated by prescribed incremental displacements at joint 55 of the model. At each displacement increment, upon determining the deformed shape of the frame, flexural and shear stiffnesses of all sub-elements are updated. Compatibility and equilibrium checking is carried out for the frame structure in each iteration.

Comparison between experimental and analytical results of lateral displacement at joint J5 is presented in Figure 5. The numerical results of layered finite element analysis by Vecchio and Emara (1992) are included in the figure. It can be seen from Figure 5 that
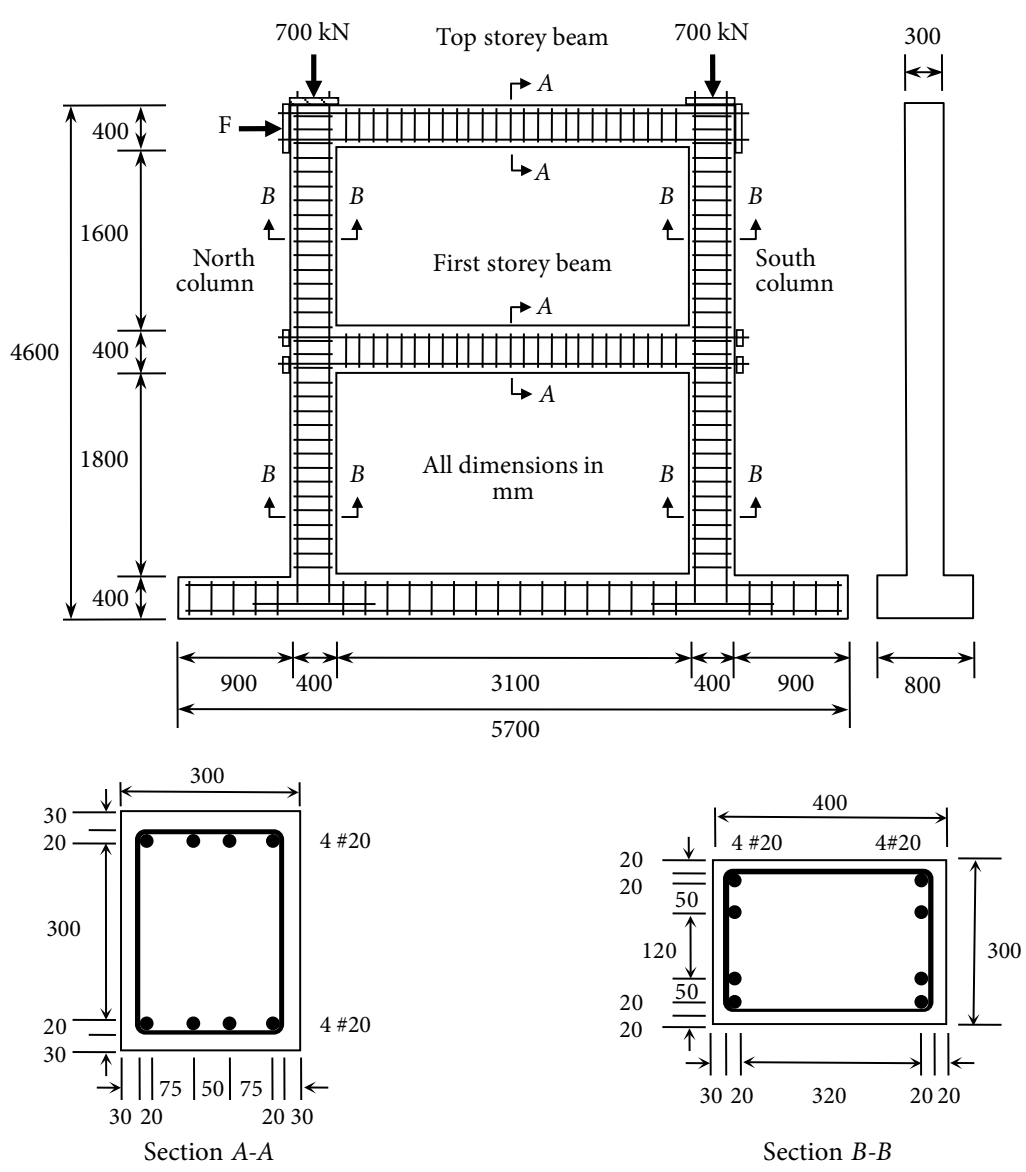

Fig. 3. Details of RC frame 


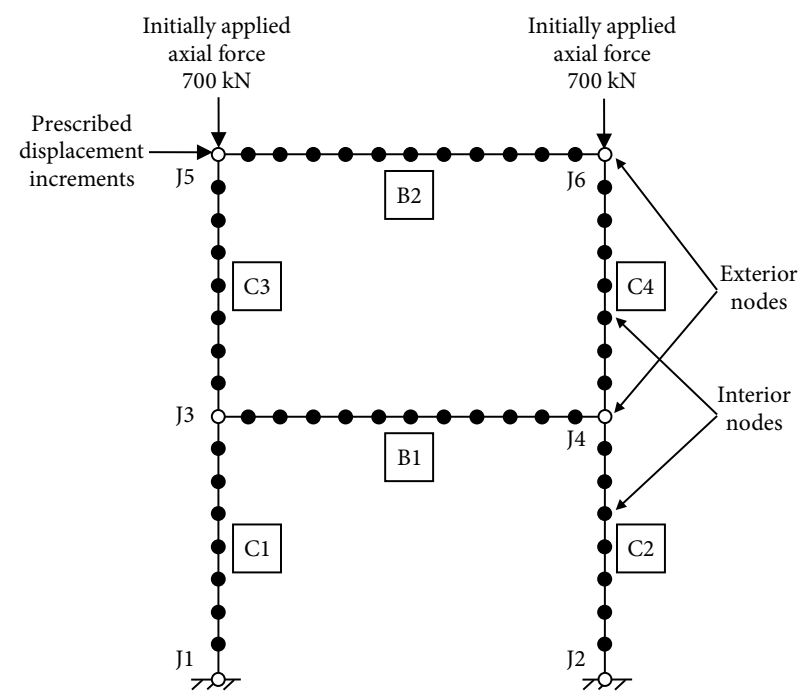

Fig. 4. Geometry of frame member analysis model

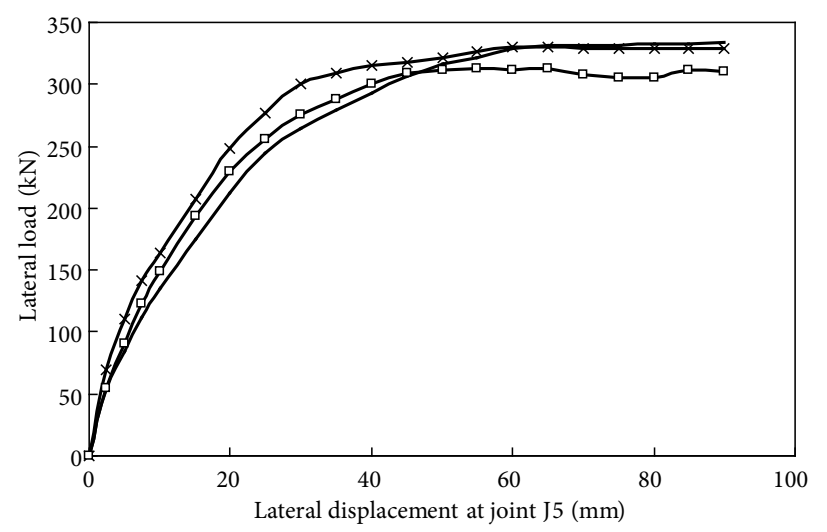

Experiment (Vecchio and Emara 1992)
$\square \quad$ Layered finite element analysis (Vecchio and Emara 1992)
$\square-$ Nonlinear multilevel analysis

Fig. 5. Load-displacement curves of RC frame

the load-displacement curve obtained from nonlinear multilevel analysis closely resembles the experimental load-displacement curve. The analytical value of ultimate load capacity is approximately $7 \%$ lower than the experimental value. In contrast, the layered finite element analysis gave accurate prediction of the ultimate load capacity, but the overall load-displacement curve deviated more significantly from the experimental results. On the whole, the accuracy of nonlinear multilevel analysis is highly desirable.

\section{Conclusions}

In this study, a nonlinear multilevel analysis method for reinforced concrete (RC) frames has been developed whereby the frame member is divided into sub-elements and member analysis is undertaken in conjunction with sectional analysis to evaluate the load-deflection response. Formulations for the nonlinear substructuring technique and the static condensation procedure have been presented. The method is computationally efficient compared to nonlinear finite element analysis. Moreover, with the unloading and reloading behaviour of concrete and steel reinforcement taken into consideration, the method has good capability to simulate nonlinearities of RC structures that arise not only from the material constitutive modelling and stiffness degradation, but also from cracking and plastic hinging. Numerical example of a RC frame specimen tested in the literature has been presented to demonstrate the applicability of the nonlinear multilevel analysis, the results of which are found to be in close agreement with the experimental results.

\section{References}

Bayrak, O.; Sheikh, S. A. 1997. High strength concrete columns under simulated earthquake loading, ACI Structural Journal 94(6): 708-722.

Corley, W. G. 1966. Rotational capacity of reinforced concrete beams, Journal of Structural Division, ASCE 92(5): 121-126.

Ding, Y.; Esping, B. J. D. 1991. An improved multilevel optimization approach, Computers and Structures 38(5/6): 557567. http://dx.doi.org/10.1016/0045-7949(91)90007-9

Dodds, R. H.; Lopez, L. A. 1980. Substructuring in linear and nonlinear analysis, International Journal for Numerical Methods in Engineering 15(4): 583-597.

http://dx.doi.org/10.1002/nme.1620150409

Guo, Z. H.; Zhang, X. Q. 1987. Investigation of complete stressdeformation curves of concrete in tension, ACI Materials Journal 84(4): 278-285.

Huang, J.; Wang, T. L. 1993. Buckling analysis of large and complex structures by using substructuring techniques, Computers and Structures 46(5): 845-850. http://dx.doi.org/10.1016/0045-7949(93)90146-5

Lai, J. Y.; Booker, J. R. 1991. A residual force finite element approach to soil-structure interaction analysis, International Journal for Numerical and Analytical Methods in Geomechanics 15(3): 181-203. http://dx.doi.org/10.1002/nag.1610150304

Lam, J. Y. K. 2009. Full-range analysis of reinforced concrete members and frames: PhD thesis. The University of Hong Kong, Hong Kong. 217 p.

Lam, J. Y. K.; Ng, P. L.; Kwan, A. K. H. 2007. Nonlinear multilevel analysis of reinforced concrete beams, in B. H. V. Topping (Ed.). Proceedings of the $11^{\text {th }}$ International Conference on Civil, Structural and Environmental Engineering Computing, 18-21 September 2007, St. Julians, Malta. 16 p. http://dx.doi.org/10.4203/ccp.86.164

Leung, A. Y. T. 1989. Multilevel dynamic substructures, International Journal for Numerical Methods in Engineering 28(1): 181-191. http://dx.doi.org/10.1002/nme.1620280113 
Leung, Y. T.; Cheung, Y. K. 1981. Dynamic analysis of frames by a two-level finite element method, Journal of Sound and Vibration 74(1): 1-9. http://dx.doi.org/10.1016/0022-460X(81)90487-9

Mattock, A. H. 1964. Rotational capacity of hinging regions in reinforced concrete beams, ACI Special Publication SP12, Proceedings of the International Symposium on Flexural Mechanics of Reinforced Concrete, November 1964, Miami, Florida, USA, 143-181.

Mattock, A. H. 1967. Discussion of "Rotational capacity of reinforced concrete beams" by W. G. Corley, Journal of Structural Division, ASCE 93(2): 399-492.

Mendis, P. 2001. Plastic hinge lengths of normal and high-strength concrete in flexure, Advances in Structural Engineering 4(4): 189-195. http://dx.doi.org/10.1260/136943301320896651

Ng, P. L. 2007. Constitutive modelling and finite element analysis of reinforced concrete structures: $\mathrm{PhD}$ thesis. The University of Hong Kong, Hong Kong. 422 p.

Park, R.; Priestley, M. J. N.; Gill, W. D. 1982. Ductility of squareconfined concrete columns, Journal of Structural Division, ASCE 108(4): 929-950.

Paulay, T.; Priestley, M. J. N. 1992. Seismic design of reinforced concrete masonry buildings. London, UK: John Wiley \& Sons. 744 p. http://dx.doi.org/10.1002/9780470172841

Paultre, P.; Legeron, F; Mongeau, D. 2001. Influence of concrete strength and transverse reinforcement yield strength on behavior of high-strength concrete columns, ACI Structural Journal 98(4): 490-501.
Przemieniecki, J. S. 1963. Matrix structural analysis of substructures, AIAA Journal 1(1): 138-147.

http://dx.doi.org/10.2514/3.1483

Roeck, G. D.; Laethem, M. V.; Sheu, C. H. 1989. Multi-level substructuring in the elasto-plastic domain, Computers and Structures 31(5): 757-765.

http://dx.doi.org/10.1016/0045-7949(89)90210-1

Row, D. G.; Powell, G. H. 1978. A substructure technique for nonlinear static and dynamic analysis. UCB/EERC-78/15. Earthquake Engineering Research Center, University of California, Berkeley, California, USA. 202 p.

Saenz, L. P. 1964. Discussion of "Equation for the stress-strain curve of concrete" by Desayi and Krishnan, ACI Journal 61(9): 1229-1235.

Tanaka, H.; Park, R. 1990. Effect of lateral confining reinforcement on the ductile behaviour of reinforced concrete columns. Research Report 90-2. University of Canterbury, Christchurch, New Zealand.

Vecchio, F. J.; Emara, M. B. 1992. Shear deformations in reinforced concrete frames, ACI Structural Journal 89(1): 46-56.

Zahn, F. A. 1985. Design of reinforced concrete bridge columns for strength and ductility: PhD thesis. University of Canterbury, Christchurch, New Zealand. 330 p.

Zahn, F. A.; Park, R.; Priestley, M. J. N. 1983. Strength and ductility of reinforced concrete piers - a summary report. Research Report 83-7. Department of Civil Engineering, University of Canterbury, Christchurch, New Zealand. 43 p.

Pui Lam NG. Honorary research associate at the Department of Civil Engineering, The University of Hong Kong. Visiting scholar at the Department of Bridges and Special Structures, Vilnius Gediminas Technical University, Lithuania. Chartered civil engineer. Honorary Secretary of the Hong Kong Concrete Institute. Research interests include concrete materials and concrete structures. Recipient of Certificate of Merit, The HKIE Innovation Awards for Young Members, and The HKIE Outstanding Paper Award for Young Engineers/Researchers by the Hong Kong Institution of Engineers.

Jeffery Yuet Kee LAM. PhD graduate of the Department of Civil Engineering, The University of Hong Kong. Chartered structural engineer in AECOM. Executive Board member of the Hong Kong Concrete Institute. Research interests include nonlinear analysis of reinforced concrete, constitutive modelling and ductility assessment of structural components, and earthquake resistant design of concrete structures. Recipient of The HKIE Outstanding Paper Award for Young Engineers/Researchers by the Hong Kong Institution of Engineers.

Albert Kwok Hung KWAN. Professor of the Department of Civil Engineering, The University of Hong Kong. Chartered civil engineer. Founding president of the Hong Kong Concrete Institute. Research interests include tall buildings, crack control of concrete structures, concrete materials and science. Recipient of Telford Premium by the Institution of Civil Engineers, OVM Best Paper on Prestressed Concrete - First Prize by China Civil Engineering Society, HKIE Transactions Prize, and Civil Engineering Papers of the Year (Special Award in Research Project) by the Hong Kong Institution of Engineers. 